\title{
"SANTAS CRUZES" LOCUS DE NUCLEAÇÃO DE RESTAURAÇÃO AMBIENTAL: METODOLOGIA POR ABANDONO E REGENERAÇÃO ESPONTÂNEA, UM RISCO PARA O BIOMA MATA ATLÂNTICA
}

\author{
Cristiane da Silva Jacob ${ }^{1}$ \\ José Eduardo de Freitas ${ }^{2}$ \\ Paulo Sergio de Sena ${ }^{3}$
}

Resumo: Uma expressão cultural-religiosa "Santa Cruz" (altar com descarte de imagens de valor sacro para a Igreja Católica) tem possível valor deletério sobre o Hotspot ambiental Mata Atlântica, na região Metropolitana do Vale do Paraíba e Litoral Norte Paulista. Material e Métodos: foi construído um modelo de Santa Cruz similar às encontradas na Mata Atlântica e, durante seis meses (outono/inverno) foram medidas as alterações de $\mathrm{pH}$ do solo e a retenção de água, pós chuva e em período de seca, pelas imagens de gesso. Os resultados mostraram que nesses lócus o pH do solo oscilou entre 6,3 e 7,0; a umidade retida nas peças de gesso aumentou a massa das imagens em ambos os períodos. Concluiu-se que estas Santas Cruzes podem se transformar em ambientes semelhantes ao modelo de nucleação por abandono usado para a recomposição florestal de áreas degradados, mas também permite o desenvolvimento de Espécies Invasoras ao Bioma, oferecendo riscos antrópicos ao Hotspot.

Palavras-chave: Etnoecologia; Hotspot ambiental; Mata Atlântica; Vale do Paraíba; Imagens sacras.

\footnotetext{
1 Licenciatura em Biologia/Centro Universitário Teresa D’Ávila, Brasil. E-mail: cristiane_silva_jacob@hotmail.com.

2 Licenciatura em Biologia/Centro Universitário Teresa D’Ávila, Brasil. E-mail: zee.freitas@ibest.com.br.

${ }^{3}$ Mestrado em Design, Tecnologia e Inovação/Laboratório de Etnoecodesign/Centro Universitário Teresa D’Ávila. Brasil. E-mail: pssena@gmail.com.
} 